\title{
La riqueza regalada a la gran minería del cobre en Chile: nuevas estimaciones, 2005-2014
}

\author{
Gino Sturla Zerene, Ramón E. López, Simón Accorsi O. \\ y Eugenio Figueroa B. ${ }^{1}$
}

\section{Resumen}

En este trabajo se estiman las rentas económicas de los diez yacimientos que constituyen la gran minería privada del cobre en Chile. La metodología utilizada asegura un cálculo conservador e incluye dos correcciones ignoradas en la literatura: el resarcimiento de los gastos en exploración y la indispensable compensación por la volatilidad del precio del cobre. Las estimaciones muestran que la riqueza regalada a estas empresas alcanza un valor piso de 114.000 millones de dólares entre 2005 y 2014. Estas rentas son neutras en relación con las decisiones de inversión y producción, es decir, si estas empresas privadas hubiesen pagado al fisco chileno el monto calculado, su inversión y producción totales no habrían cambiado, pero el país habría podido disponer de esos cuantiosos recursos. Además, en ausencia de cualquier otra distorsión, estas empresas igualmente habrían tenido rentabilidades equivalentes a las que hubiesen logrado en una economía de competencia perfecta.

\section{Palabras clave}

Cobre, minería, sector privado, ingresos, medición, recursos naturales, precios, ingresos fiscales, Chile

\section{Clasificación JEL}

Q30, Q32, Q33

\section{Autores}

Gino Sturla Zerene es candidato a Doctorado en Economía en el Departamento de Economía de la Facultad de Economía y Negocios de la Universidad de Chile. Correo electrónico: gsturla@fen.uchile.cl.

Ramón E. López es Profesor Titular y Director Académico de los programas de Magíster y Doctorado en Economía del Departamento de Economía de la Facultad de Economía y Negocios de la Universidad de Chile. Correo electrónico: ramlopez@ fen.uchile.cl.

Eugenio Figueroa B. es Profesor Titular y Director del Departamento de Economía de la Facultad de Economía y Negocios de la Universidad de Chile. Correo electrónico: efiguero@fen.uchile.cl.

Simón Accorsi O. es candidato a Doctorado en Economía en el Departamento de Economía de la Facultad de Economía y Negocios de la Universidad de Chile. Correo electrónico: saccorsi@fen.uchile.cl.

\footnotetext{
1 Los autores agradecen a los siguientes programas e instituciones: al programa Becas de Doctorado Nacional de la Comisión Nacional de Investigación Científica y Tecnológica (Conicyt), que beneficia a Gino Sturla Zerene; al Departamento de Economía de la Facultad de Economía y Negocios (FEN) de la Universidad de Chile, por la Beca de Arancel que beneficia a Simón Accorsi O. y a Gino Sturla Zerene, y al Centro de Economía de los Recursos Naturales y el Medio Ambiente (CENRE), de la FEN, por el apoyo al proyecto de investigación Rentas Económicas de los Recursos Naturales de Chile, del que este trabajo forma parte.
} 


\section{Introducción}

"... todo chileno tiene que reflexionar cómo usar un peso adicional en darle un peso más a un puente, a un colegio, a un trabajador del sector público, a un pensionado..."

Rodrigo Valdés, Ministro de Hacienda de Chile, 2015-2017, Diario La Tercera, 25 de agosto de 2016, Santiago.

“...no debemos consentir que esta vasta y rica región sea convertida en una simple factoría extranjera..."

José Manuel Balmaceda, Presidente de Chile, 1886-1891, "Mensaje al Congreso", 1 de junio de 1889, Santiago.

La gran minería privada del cobre produce alrededor del 60\% del total del cobre producido en el país y está constituida fundamentalmente por diez grandes empresas transnacionales. La mayor parte del cobre que estas empresas producen se exporta como concentrado, lo que implica un mínimo nivel de elaboración del producto. Aparte de las grandes minas privadas, existe una empresa pública, Corporación Nacional del Cobre de Chile (CODELCO), que produce alrededor de un tercio de la producción total de cobre del país.

El cobre ha generado una parte muy significativa de los ingresos tributarios de Chile. Sin embargo, el grueso de la contribución del cobre al Estado chileno proviene de la empresa estatal (alrededor del 60\% del total), mientras que las diez grandes mineras privadas contribuyen menos de la mitad de lo que ella paga. Es decir, la tasa efectiva de impuesto de CODELCO es casi cuatro veces mayor por tonelada de cobre producida que la tasa de las grandes mineras privadas.

Esto constituye una importante motivación para este estudio: ¿por qué las grandes empresas privadas pagan impuestos tan inferiores a los de la empresa estatal? Y esto a pesar de que CODELCO tiene minas mucho más antiguas que las empresas privadas y con una ley mineral bastante inferior en promedio.

Además, a pesar de esto, la pesada carga tributaria de CODELCO no ha sido obstáculo para que dicha empresa mantuviera una situación financiera bastante sana la mayor parte de los años. Esto implica que las mineras privadas podrían contribuir mucho más de lo pagan al Estado chileno, sin poner en riesgo su viabilidad económica y obteniendo tasas normales de retorno a su capital.

Es decir, existe la presunción de que las mineras privadas se están apropiando de un volumen cuantioso de rentas económicas. En este trabajo se mide el valor de las rentas de las que se apropian, utilizando supuestos muy conservadores en la estimación, a fin de proveer un valor mínimo.

En función de este objetivo, el presente trabajo se organiza de la siguiente manera: en la sección II se presenta el marco conceptual que se ha de emplear, enfatizando en la noción de renta económica, la relación de esta con los recursos naturales y la renta económica minera, además de hacer una breve reseña de la literatura sobre esta materia en el caso de Chile; en la sección III se describe el proceso de estimación de las rentas mineras que hace el Banco Mundial, que constituyen el conjunto de datos que se utiliza en este estudio; en la sección IV se presenta la metodología de cálculo de las rentas, y en la sección $V$ se exponen los resultados. Por último, a modo de conclusión, se ofrece un conjunto de reflexiones finales. 


\section{Marco conceptual}

\section{Renta económica}

La definición clásica de renta económica se refiere a la retribución económica que un factor de producción específico percibe en exceso, es decir, por encima del pago mínimo requerido para seguirle dando el mismo uso. Considerando todos los factores de producción, la renta económica asociada a una empresa productiva se puede entender como el pago que excede el monto mínimo necesario para que ella permanezca en una determinada actividad económica. Véase una discusión sobre el origen y el desarrollo teórico posterior de este concepto en las cartas de David Ricardo, 1810-1815, recopiladas por Piero Sraffa (Ricardo, 2005), en la revisión de la literatura de Tollison (1982), y en los estudios de Shepherd (1970) y Hammes (1985), entre otros.

En el concepto de renta económica el costo de oportunidad de todos los recursos productivos utilizados está ya descontado. Dado que en los costos de oportunidad se incorpora la ganancia que se hubiera obtenido al darle a los recursos destinados a cierta actividad el mejor uso alternativo, la renta económica representa un excedente por encima de la ganancia necesaria para asignar los recursos a la actividad en cuestión. En términos más simples, la renta es el monto que sobra del valor de la producción después de descontar todos los costos, incluido el que supone el retorno normal al capital y las primas por los riesgos pertinentes. Wessel (1967) distingue entre la noción de renta ricardiana y renta paretiana, y enfatiza que esta última se calcula deduciendo los costos de oportunidad. En este estudio, el concepto de renta económica se utiliza en su acepción paretiana.

\section{Renta económica y recursos naturales}

Una característica importante de las economías basadas en recursos naturales es que tienden a generar cuantiosas rentas económicas, las cuales pueden engrosar el retorno del capital que los explota y elevarlo a niveles muy superiores a la rentabilidad normal. La renta económica que generan las actividades en las que los recursos naturales, renovables o no renovables, se extraen directamente constituye el valor de escasez o valor in situ de dichos recursos. De esto se desprende que dicha renta es lo que puede cobrar de forma legítima el dueño del recurso natural a quien lo utilice en un proceso productivo. El presente estudio se enfoca en el cálculo de esta renta en Chile. En particular, se estudia la renta de las diez empresas de la gran minería privada del cobre, que en adelante llamaremos GMP-10.

\section{Origen de la renta económica minera}

Los recursos minerales presentan una particularidad respecto de otros recursos naturales: requieren de una fase previa a la de extracción o explotación, que se denomina "exploración minera". Encontrar minerales ha sido una tarea históricamente dificultosa, costosa y con bajas probabilidades de éxito. En el caso específico de la minería, es posible distinguir dos regímenes de exploración:

i) Régimen de libre entrada en la exploración: en esta forma de operación, existe competencia perfecta en el mercado de la exploración, por lo que las rentas económicas asociadas a los agentes que exploran tienden a disiparse en el largo plazo.

ii) Régimen con barreras a la entrada en la exploración: esta situación se puede dar por mecanismos de cabildeo que impiden el libre acceso a la obtención de concesiones exclusivas de exploración, o simplemente por el hecho de mantener y hacer uso de los derechos derivados de concesiones previamente entregadas por el Estado. En ambos casos, el efecto final de facto 
es la existencia de barreras a la entrada en la exploración, que se convierten, también de facto, en barreras a la entrada en la extracción o explotación del mineral. Esta situación genera una escasez artificial que tiene su origen en aspectos institucionales y constituye una fuente de apropiación de las rentas por parte de las empresas exploradoras y extractoras del recurso. Es importante señalar que las rentas originadas en este régimen no se disipan como en el caso de la libre entrada: las empresas que gozan de acceso exclusivo al mineral tienden a apropiarse de estas rentas. Además, dada la heterogeneidad de los yacimientos y la escasez natural del recurso, la existencia de estas rentas no promueve más inversión. Esto se debe a que la rentabilidad del capital que se obtiene en las minas en explotación rara vez se puede replicar, porque los costos de explorar y explotar nuevos yacimientos potenciales suelen ser mayores que los de los yacimientos ya descubiertos y en explotación.

En este estudio se considera el segundo régimen, pues Chile posee una legislación que otorga concesiones de exploración y explotaciones mineras exclusivas, gratuitas y en perpetuidad. En 2013, el $42 \%$ de la superficie total del país ya estaba concesionada y correspondía a todas las zonas con potencial minero (SERNAGEOMIN, 2013). En Chile, entonces, el cobre constituye un recurso cuya escasez está determinada por las barreras de entrada a las actividades de exploración, que otorgan exclusividad gratuita a cierto número limitado de empresas. En el caso de la GMP-10, estas empresas son dueñas de la concesión de exploración y explotación, lo que les permite retener las rentas.

\section{Nomenclatura que se usará en el estudio}

- Renta minera total BM: corresponde a la renta calculada por el Banco Mundial en relación con toda la actividad minera que se realiza en Chile; los valores estimados se encuentran en Banco Mundial (2016).

- $\quad$ Renta minera BM GMP-10: es aquella parte de la renta minera total BM asociada a las empresas que explotan los diez yacimientos que constituyen la gran minería privada del cobre en Chile.

- Renta compensada GMP-10: es la renta remanente que resulta de tomar la renta minera BM GMP-10 (en cuyo cálculo ya se han sustraído todos los costos de producción al valor de las ventas del mineral) y restarle dos retornos compensatorios adicionales que hasta ahora no se habían considerado en ningún estudio sobre Chile. Estos corresponden a:

i) el retorno compensatorio por el alto riesgo asociado a realizar la actividad de exploración minera, y

ii) el retorno compensatorio por el alto riesgo asociado a la volatilidad del precio de las materias primas (el cobre) en el mercado internacional.

- Renta graciosa apropiada GMP-10: resulta de restar a la renta compensada GMP-10 la recaudación tributaria que el Estado de Chile extrae a la gran minería privada del cobre. Corresponde a la renta económica en su acepción más rigurosa, por lo que, si se la extrajera mediante algún gravamen impositivo, no generaría distorsiones en la economía. La hemos llamado "graciosa" pues esta renta, que debería quedar en manos del dueño del mineral (el Estado de Chile), se cede por gracia (se regala) a las empresas que explotan este recurso.

\section{Estudios efectuados sobre la renta minera en Chile}

Son pocos los trabajos en los que se han estudiado las rentas mineras en Chile, a pesar de su trascendental relevancia para la economía del país. Hoy en día, el estudio más importante corresponde sin duda al que llevó a cabo el Banco Mundial (2011), que se describe con más detalles en la sección III. 
En los últimos años se han hecho estimaciones de la renta minera, pero estas contienen errores metodológicos significativos. Por ejemplo, al calcular la renta económica, Poblete (2015) considera las ventas que las empresas mineras declaran y no la producción total del cobre y los demás minerales a precio de mercado. Esto no es congruente con la teoría económica y genera una severa distorsión, debido a que una parte significativa de las ventas se declara a precios de transferencia, que generalmente son inferiores al precio de mercado (COCHILCO, 2015; Correa, 2016).

En ninguno de los estudios mencionados se consideran los gastos en exploración, que deben ser amplificados ex ante, pues en la exploración existe una alta probabilidad de fracaso que se debe compensar desde el punto de vista económico. Un segundo aspecto que no se considera es la compensación por la volatilidad de los precios del cobre, lo que implica evaluar las rentas a precios de tendencia en lugar de a precios observados. No hacer esto puede causar una sobrestimación de las rentas cuando se las mide en un período de auge o superciclo de los precios de los minerales.

\section{Una metodología moderna}

La metodología utilizada permite asegurar que las rentas estimadas en este trabajo correspondan a un valor "piso" o mínimo. A estos efectos, realizamos aquí dos importantes correcciones que por lo general se ignoran en la literatura -inclusive en las estimaciones del Banco Mundial y la Organización para la Cooperación y el Desarrollo Económicos (OCDE) - , que reducen significativamente el monto estimado de las rentas:

i) Gasto en exploración: para mantener el potencial productivo de largo plazo, las empresas que extraen el cobre deben gastar mucho en labores de exploración, al objeto de reemplazar yacimientos que se van agotando. A menudo, las exploraciones mineras no resultan exitosas, lo que implica que estas actividades están sujetas a un alto riesgo que deberá premiarse con una mayor tasa de retorno ex ante. Así, en el cálculo de la renta económica no solo se deben descontar los costos de exploración observados, sino que en su valoración se debe incluir, además, un premio por los riesgos ex ante de estos gastos.

ii) Volatilidad del precio de los productos básicos: los precios de las materias primas, particularmente del cobre, sufren importantes fluctuaciones, con períodos muy bajos y otros altos a los que se les llama auge. Esto implica que las rentas que pueden parecer excesivas en períodos de auge pueden, en parte, ser meramente compensatorias de las pérdidas que pueden ocurrir en períodos de precios bajos. Medir las rentas, por ejemplo, en períodos de precios muy altos, como es el caso de este estudio, puede inducir a su sobrestimación y, por tanto, gravarlas por completo sería distorsionante. Este problema se aborda removiendo del precio del cobre el efecto de las fluctuaciones de corto plazo y utilizando precios de tendencia en lugar de los observados. Las rentas así estimadas corresponden a rentas de largo plazo.

Esta metodología implica estimar el valor mínimo de la renta comparada con las medidas más convencionales de ella. Esto puede representar una desventaja, ya que se tiende a subestimar el verdadero valor de la renta económica. Sin embargo, nuestro interés es precisamente estimar la renta de la manera más conservadora posible, para obtener una frontera mínima de ella. Desde el punto de vista de las políticas públicas, es probable que el riesgo de no gravar una parte de la renta traiga menores consecuencias negativas que gravarla en exceso como resultado de estimaciones demasiado altas. En el primer caso, al subestimar la renta, solo se causa un efecto distributivo porque se recauda menos de lo que se podría. En el segundo caso, si se sobrestima la renta, al gravarla se pueden provocar pérdidas de eficiencia económica.

Así, la renta económica estimada en este trabajo - la renta graciosa apropiada GMP-10 - se puede definir como el retorno del que se apropian las más grandes empresas mineras, que supera 
todo lo que estas necesitan para mantener intactos sus incentivos, así como sus niveles de inversión y producción, en el largo plazo.

El camino metodológico que se recorre en este trabajo es el siguiente. A partir de la medición de la renta minera total de Chile realizada por el Banco Mundial, se obtiene la parte que corresponde a la GMP-10, que está implícita en el cálculo que hace dicha institución y asciende a 204.000 millones de dólares en el período de 2005 a 2014². A este valor se le descuenta el monto requerido para compensar la incertidumbre del gasto en exploración (algo más de 18.000 millones de dólares) y el monto destinado a compensar la volatilidad del precio del cobre (casi 30.000 millones de dólares). Se obtiene así la renta compensada GMP-10, que es de 156.000 millones de dólares. A esta renta se le restan los impuestos pagados por la GPM-10, casi 42.000 millones de dólares, y se obtiene así la renta graciosa apropiada GMP-10, que equivale a 114.000 millones de dólares. Este monto equivale a casi seis veces el total de los fondos soberanos actuales del país (Ministerio de Hacienda, 2015).

\section{Las rentas mineras según el Banco Mundial}

\section{Aspectos generales}

En el estudio The Changing Wealth of Nations: Measuring Sustainable Development in the New Millennium (Banco Mundial, 2011), el Banco Mundial calculó las rentas mineras de distintos países -entre ellos, Chile-, y estas se han actualizado hasta el año 2014. Esta base de datos oficiales presenta una extensión de 45 años y está en proceso de actualización permanente.

En la metodología de cálculo (Banco Mundial, 2011; Brandt, Schreyer y Zipperer, 2013) se considera lo siguiente:

- $\quad$ La producción de minerales, en unidades equivalentes de fino, asociada a los yacimientos o minas situados en el país.

- $\quad$ El precio observado en el mercado internacional de los minerales, que permite obtener una estimación del valor de las ventas que, en general, es diferente al que declaran las empresas.

- Los costos totales de la producción minera en los yacimientos o minas, incluido el costo de oportunidad del capital (Brandt, Schreyer y Zipperer, 2013).

En lo que respecta a Chile, en este estudio se consideran, además del cobre, los siguientes productos mineros: estaño, oro, plomo, zinc, hierro, níquel, plata, bauxita y fosfato. Las rentas del cobre dominan ampliamente - más del 95\% - en comparación con las asociadas a los demás minerales, sobre todo en el período de 2005 a 2014 (Brandt, Schreyer y Zipperer, 2013). Por otra parte, la mayoría de los minerales considerados corresponde a subproductos de la gran minería del cobre y por ende están presentes, aunque en menor medida, en las rentas de estas empresas. Cabe destacar que el aporte de estos minerales a las rentas calculadas está subestimado, pues los subproductos de la gran minería privada del cobre se han subdeclarado de manera sistemática como consecuencia de la falta de mediciones hechas por laboratorios que sean genuinamente independientes de las empresas mineras (Castillo, 2015).

Un punto importante es que las rentas del Banco Mundial no corresponden a rentas económicas en su definición más estricta - la que se utiliza en este trabajo -, pues en ellas no se sustraen los retornos exigibles como compensación por los riesgos del gasto en exploración y la volatilidad del precio internacional de los minerales. En este trabajo se abordan estos dos aspectos y se efectúan los cálculos correspondientes.

2 En este trabajo se utilizan siempre dólares de los Estados Unidos de América correspondientes a octubre de 2016. 


\section{Rentas mineras en Chile comparadas con las de otros países cupríferos}

En 2014, en Chile se extrajo el 31\% del total del cobre producido en el mundo. En el gráfico 1 se presentan los diez países que ese año extrajeron la mayor cantidad de cobre a nivel mundial.

\section{Gráfico 1}

Participación de los mayores productores de cobre en la producción mundial de este mineral, 2014

(En porcentajes)

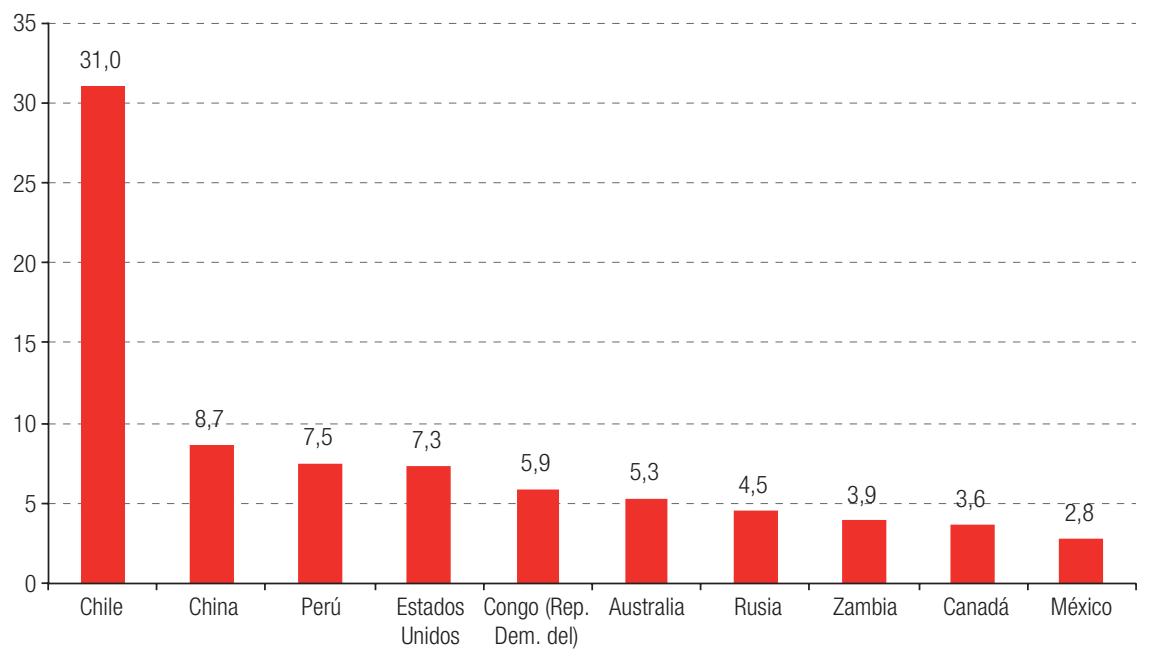

Fuente: Elaboración propia, sobre la base de Banco Mundial, Indicadores del Desarrollo Mundial, 2016.

En el gráfico 2 se muestran las rentas mineras de 1970 a 2014, calculadas por el Banco Mundial (Banco Mundial, 2016) en relación con los seis países donde más cobre se producía en ese último año. Las rentas se expresan como proporción del producto interno bruto (PIB). En este gráfico es importante destacar que, en Chile, las rentas mineras superaron el 5\% del PIB casi todos los años, aun en períodos en los que el precio del cobre era muy bajo. Esto sugiere que la generación de rentas económicas no es solo un fenómeno cíclico, propio de períodos de bonanza del mercado del cobre, sino evidentemente una cuestión de largo plazo. 


\section{Gráfico 2}

Rentas anuales de la minería como proporción del PIB en los seis países que más cobre producían en 2014, 1970-2014a

(En porcentajes)

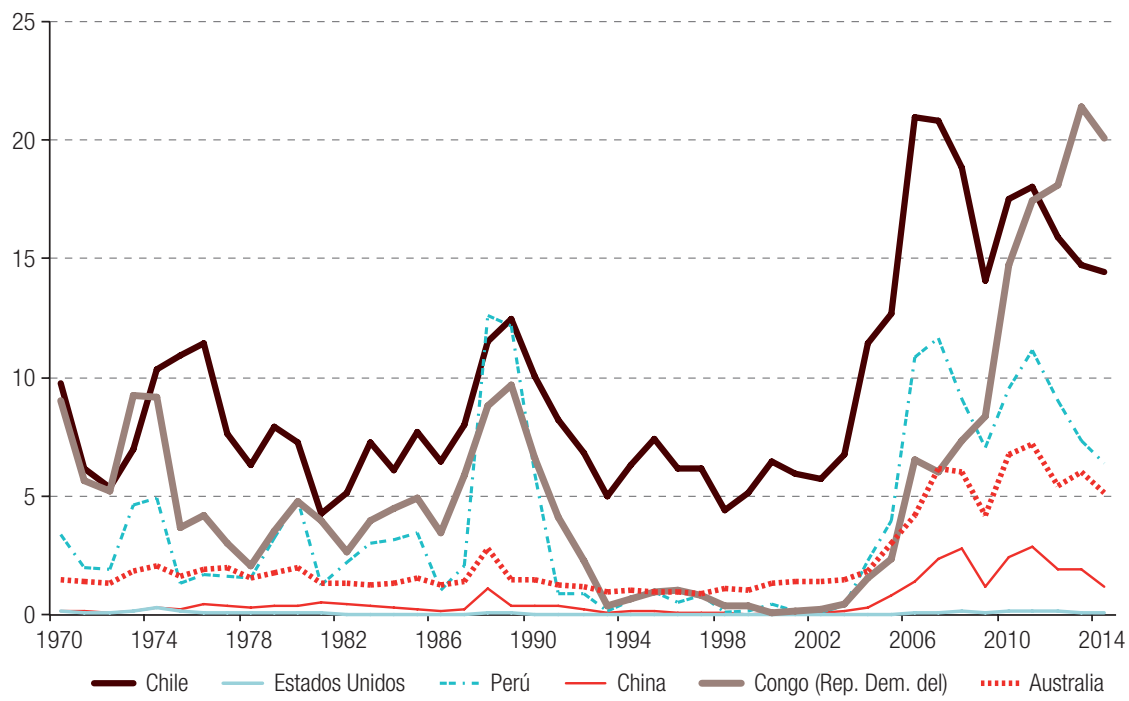

Fuente: Elaboración propia, sobre la base de Banco Mundial, Indicadores del Desarrollo Mundial, 2016.

PIB significa producto interno bruto.

\section{Rentas mineras estimadas por el Banco Mundial en relación con Chile}

En el gráfico 3 se presenta el monto de las rentas económicas mineras del período de 2005 a 2014 que el Banco Mundial estimó en relación con Chile (Banco Mundial, 2016). El monto total corresponde a 389.000 millones de dólares, con un promedio anual de 38.900 millones, cifra que corresponde al $17 \%$ del PIB de Chile.

Gráfico 3

Chile: renta económica anual de la minería estimada por el Banco Mundial, 2005-2014 (En miles de millones de dólares) ${ }^{a}$

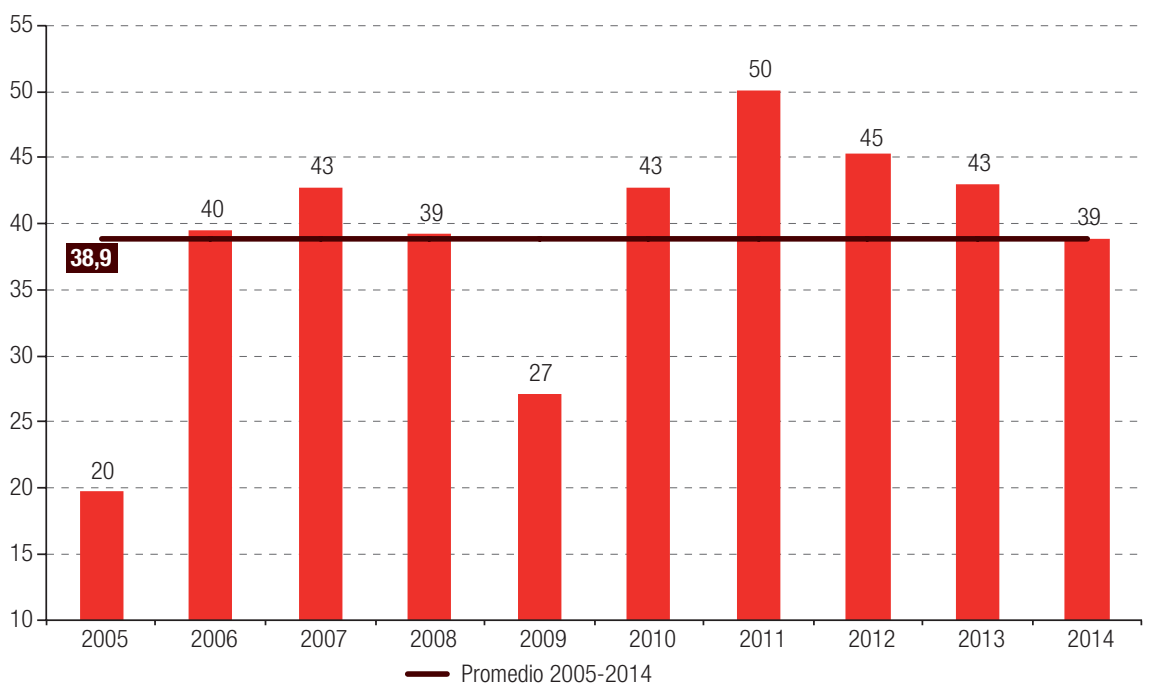

Fuente: Elaboración propia, sobre la base de Banco Mundial, Indicadores del Desarrollo Mundial, 2016.

a En dólares de octubre de 2016. 


\section{Metodología de cálculo de la renta graciosa apropiada GMP-10}

\section{Aspectos generales}

Entre 2005 y 2014, la GMP-10 ha representado, en promedio, el 57\% de la producción de cobre de Chile. Esta producción, sumada a la de CODELCO, alcanza el 88\% de la producción del país. El 12\% restante corresponde a minas de menor envergadura. Si bien existen yacimientos, como Spence, El Tesoro y Esperanza, que tienen producciones similares a las de las empresas de la GMP-10, a estos aún no se los cataloga oficialmente dentro de este grupo (COCHILCO, 2015). Esto último constituye la primera razón por la cual dichos yacimientos no se han incluido en este estudio. La segunda razón es que dos de ellos se empezaron a explotar después de 2005.

El objetivo es estimar la renta graciosa apropiada GMP-10 de manera económicamente coherente. Con ese fin, se han definido cuatro etapas, partiendo de los montos de la renta minera total que informa el Banco Mundial:

i) Determinación de la renta minera BM (Codelco + GMP-10)

ii) Obtención de la renta minera BM GMP-10

iii) Estimación de la renta compensada GMP-10

iv) Cálculo de la renta graciosa apropiada GMP-10

En esta sección se desarrolla la metodología correspondiente a las primeras tres etapas definidas. La última etapa solamente supone descontar, de la renta compensada GMP-10 obtenida en la etapa 3, los impuestos pagados por la GMP-10 al Estado de Chile.

\section{Metodología de cálculo}

La renta minera medida por el Banco Mundial en relación con Chile (Banco Mundial, 2016) corresponde al total de la renta generada por el sector minero de la economía chilena, por lo que se ha establecido una metodología con el objeto de obtener la renta minera BM GMP-10 y posteriormente la renta compensada GMP-10. En esta sección se describe la metodología de cálculo empleada. Un aspecto fundamental de dicha metodología es que el valor de las ventas del mineral se mide sobre la base de los precios internacionales del metal y no de las ventas que declaran las empresas, como se ha hecho en otros estudios. En esto hemos seguido el método implementado por el Banco Mundial (2011) y por Brandt, Schreyer y Zipperer (2013). Este enfoque tiene la ventaja de ser independiente de los informes de las empresas, que a menudo subvaloran las ventas a fin de reducir sus tributos.

\section{a) CODELCO más GMP-10}

Se asume que la renta estimada por el Banco Mundial en relación con CODELCO y la GMP-10 es equivalente a la proporción de estas en la producción total de cobre del país en cada año. Esta forma de obtener la renta asociada a la gran minería del cobre (pública y privada) es coherente y corresponde a una metodología conservadora. En el estudio de Brandt, Schreyer y Zipperer (2013) se demuestra que las rentas mineras asociadas a la gran minería del cobre corresponden al $90 \%$ de las rentas generadas por todo el capital natural contabilizado en Chile. Por otro lado, a partir de los datos del Banco Mundial (2016), se observa que, en el período de 2005 a 2014, el 89\% de la renta de los recursos naturales del país corresponde a renta minera. Para obtener la renta de la gran minería se 
debe excluir de este monto las rentas de la mediana y pequeña minería del cobre. Por ello, sobre la base de los dos estudios antemencionados, se ha definido el siguiente criterio metodológico: en cada año, de la renta minera que informa el Banco Mundial, la proporción correspondiente a la gran minería del cobre (pública y privada) será equivalente a la participación de esta última en la producción total de cobre en Chile. Este supuesto es conservador, ya que las rentas de la gran minería tienden a ser superiores a las de las minas pequeñas y medianas como proporción de su producción.

La renta minera del Banco Mundial asociada a la GMP-10 $\left(R_{b m, G m p 10}\right)$ y a la estatal CODELCO $\left(R_{b m, C o d}\right)$ se puede expresar como:

$$
R_{b m, G m p 10}+R_{b m, C o d}=(1-B) \cdot R_{b m, T o t a l}
$$

donde,

$B=$ proporción de la renta minera total del Banco Mundial que no corresponde a GMP-10 ni a CODELCO, y

$R_{b m, \text { Total }}=$ renta minera total del Banco Mundial.

\section{b) Renta minera BM GMP-10}

La renta minera BM GMP-10 se puede expresar en términos de la renta minera BM CODELCO, a partir de la ecuación (1). A los efectos de calcular esta última renta, se utilizará el mismo procedimiento del Banco Mundial (Brandt, Schreyer y Zipperer, 2013).

$$
R_{b m, C o d}=p \cdot q_{C o d}+S_{C o d}-c_{C o d} \cdot q_{C o d}-(r+\delta) \cdot K_{C o d}
$$

donde,

$p=$ precio de mercado del cobre,

$q_{\text {Cod }}=$ producción de cobre de CODELCO,

$S_{\text {Cod }}=$ ingresos adicionales por subproductos de CODELCO,

$c_{C o d}=$ costo total unitario de explotación de CODELCO ${ }^{3}$,

$r=$ tasa normal de retorno del capital,

$\delta=$ tasa de depreciación del capital, y

$K_{\text {Cod }}=$ stock de capital de CODELCO.

Así, es posible obtener una expresión de la renta minera BM GMP-10.

$$
R_{b m, G m p 10}=(1-B) \cdot R_{b m, T o t a l}-R_{b m, C o d}
$$

\section{c) Renta compensada GMP-10}

La renta compensada GMP-10 $\left(R_{C, G m p 10}\right)$ es la renta del Banco Mundial correspondiente a la GMP-10, con dos correcciones adicionales: premio por riesgo en exploración $(\eta)$ y compensación por la volatilidad del precio del cobre $(\phi)$.

\footnotetext{
3 Este costo total de explotación no corresponde al costo directo unitario de explotación c1 que aparece más adelante, puesto que se han incorporado las correcciones asociadas a la venta de cobre en forma de concentrado. En el anexo A1 se detalla la metodología que se utilizó a los efectos de incorporar el hecho de que, en el período, CODELCO haya vendido en promedio un $14 \%$ de su cobre sin refinarlo.
} 


$$
R_{C, G m p 10}=R_{b m, G m p 10}-\eta-\phi
$$

El premio por riesgo en exploración de la GMP-10 $(\eta)$ se define sobre la base de López y Figueroa (2014). Este premio corresponde a la amplificación del gasto en exploración, según la probabilidad de éxito en las labores y la tasa de retorno al capital, menos el gasto de exploración declarado:

$$
\eta=E_{G m p 10}\left(\frac{r}{1-\theta}-1\right)
$$

donde,

$E_{G m p 10}=$ gasto en exploración GMP-10

$(1-\theta)=$ probabilidad de éxito en las labores de exploración de la GMP-10

Respecto a la compensación por la volatilidad en el precio del cobre $(\phi)$, esta se define a partir de la diferencia entre el precio de mercado y el precio de tendencia del cobre (detalle en la sección IV.3.c).

$$
\phi=\left(p-p_{T}\right) \cdot q_{G m p 10}
$$

donde,

$P_{T}=$ precio de tendencia del cobre

$q_{\text {Gmp10 }}=$ producción de cobre GMP-10

Así, utilizando (4), (5) y (6), se obtiene la ecuación (7), en la que se expresa la renta compensada GMP-10 en función de la renta minera BM GMP-10 y las correcciones adicionales.

$$
R_{C, G m p 10}=R_{b m, G m p 10}-E_{G m p 10}\left(\frac{r}{1-\theta}-1\right)-\left(p-p_{T}\right) \cdot q_{G m p 10}
$$

\section{Datos para el cálculo}

\section{a) Información general}

Para realizar las estimaciones requeridas se debe contar con información anual del precio internacional del cobre, así como de los costos y la producción totales, de la GMP-10 y de CODELCO. Los costos y la producción (cobre y subproductos) se han obtenido de la Comisión Chilena del Cobre (COCHILCO, 2015). El costo unitario c1 promedio de la GMP-10 es de 1,60 dólares por libra y el de CODELCO es de 1,29 dólares por libra (FCH/Alta Ley/CORFO, 2015); esto indica que la estatal es más eficiente, por lo que tendrá rentas mayores. Para calcular la renta económica anual de la GMP-10, estos costos de producción pueden representar un sesgo hacia la subestimación, ya que hay estudios de consultoras internacionales que indican que el costo de producción de CODELCO sería superior al de la GMP-10 (Mining Press, 2013). Por otra parte, la producción promedio anual de la GMP-10 fue de 3.070.000 toneladas de cobre fino por año, y la de CODELCO fue de 1.756.000. El stock de capital, tanto de CODELCO como de la GMP-10, se ha calculado sobre la base de la fórmula del perpetual inventory system.

Además, se asume que la tasa de retorno normal del capital que exigen los inversionistas en Chile es del 10\%. Esta tasa también puede inducir un sesgo hacia la subestimación de la renta anual 
de la GMP-10, ya que es superior a la tasa normal que Brandt, Schreyer y Zipperer (2013) estiman y utilizan en relación con Chile. De hecho, en algunos importantes proyectos mineros se utilizan tasas de retorno del $8 \%$ para determinar la factibilidad de los proyectos de inversión en Chile. Véase, por ejemplo, el caso del Proyecto Hidroeléctrico Alto Maipo, cuyos accionistas esperaban un retorno del 8\% de su inversión superior a 2.000 millones de dólares ${ }^{4}$. Los accionistas eran AES Gener y Antofagasta Minerals, esta última dueña de la minera Los Pelambres, que es una de las empresas de la GMP-10.

Para determinar las rentas no gravadas se usa la base tributaria que permite la ley minera, incluidas las deducciones de todos los costos variables más los costos financieros. Además, se permite deducir la depreciación de los activos de capital a una tasa acelerada que puede llegar hasta tres años en el caso de la maquinaria y los equipos.

\section{b) Retorno por gasto en exploración}

Para corregir por el retorno al capital que se exige en las actividades de exploración, se debe sustraer a la renta minera BM GMP-10 el gasto en exploración que deben realizar las empresas mineras privadas para sustentar su actividad en el tiempo. Este gasto se considera ex ante, es decir, los retornos esperados deben incluir la probabilidad de tener éxito o fracasar en las actividades de exploración, en su etapa de planeación. Como lo definen López y Figueroa (2014), debe permitirse que las empresas se apropien legítimamente de una parte de las ganancias o renta minera, a los efectos de llevar a cabo actividades de exploración minera. Dicha parte se debe calcular en función del valor esperado de la rentabilidad de la exploración realizada, incluida la probabilidad de éxito de dicha actividad.

Bartrop y Guj (2009) definen una tipología de las actividades de exploración minera. Con el propósito de no arriesgarse a que en las estimaciones efectuadas se sobrestime la renta económica que se calcula, y siguiendo a estos dos autores, se ha tipificado la GMP-10 de Chile como un industria que ha llevado y lleva a cabo de manera permanente labores de exploración en busca de yacimientos grandes, en áreas poco exploradas. Además, se considera que en la exploración se enfrenta un nivel de riesgo alto debido a que existe escaso trabajo previo, la geología es poco conocida, las áreas explorables son remotas y se requiere de programas de exploración por etapas y de gran escala. El valor más bajo de la probabilidad de éxito corresponde a 2,5\%, lo que podría considerarse como excesivamente bajo para Chile en virtud de, por ejemplo, el conocimiento actual de la geología de ciertas áreas y la cantidad de cobre que se espera que exista en el subsuelo de ciertas zonas del país. Sin embargo, este supuesto permite mantener la coherencia conceptual y no arriesgarse a incurrir en sobrestimaciones al calcular la renta neta de la GMP-10. Dado lo anterior, el premio por el riesgo en exploración, ex ante, transforma el gasto efectuado en exploración en una inversión necesaria para sustentar la actividad de explotación minera.

En el gráfico 4 se muestra el gasto en exploración anual de toda la minería privada en Chile, que aquí se asume igual al de la GMP-10, según los datos proporcionados por COCHILCO (2015). Además, se presenta el premio por el gasto en exploración, que en el caso de este estudio corresponde a tres veces el gasto declarado, dada la tasa normal de retorno del 10\% y la probabilidad de éxito del 2,5\%.

Esta forma de considerar los gastos de exploración tiene el potencial de sobrestimarlos, sobre todo porque la información disponible para calcularlos proviene de lo que declaran las propias empresas, que tienen incentivos para inflarlos de manera artificial. Desafortunadamente, esta es la única fuente de información disponible sobre gastos de exploración.

\footnotetext{
4 Esta información se obtuvo recientemente del diario El Mercurio (2017) de Chile, en el marco de la casi definitiva decisión de no construir la central hidroeléctrica y la "legítima ganancia" defendida por sus accionistas.
} 


\section{Gráfico 4}

Chile: gasto anual en exploración de la GMP-10 y retorno compensatorio que esta actividad requiere, 2005-2014

(En miles de millones de dólares) ${ }^{a}$

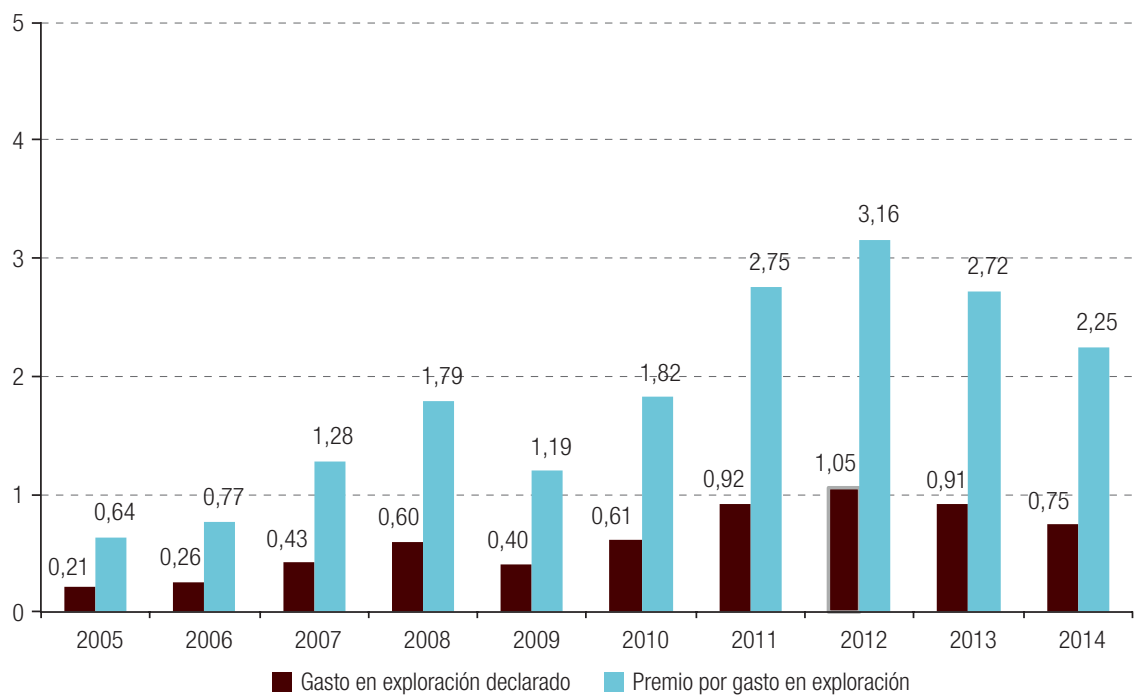

Fuente: Elaboración propia, sobre la base de Comisión Chilena del Cobre (COCHILCO), Anuario de estadísticas del cobre y otros minerales, 1996-2015, Santiago, 2015.

a En dólares de octubre de 2016.

\section{c) Retorno por volatilidad en el precio del cobre}

El precio del cobre ha exhibido fluctuaciones importantes en los últimos 45 años, durante los cuales se ha destacado un fuerte aumento a principios del siglo XXI. En esta sección se emplean una serie de 45 años del precio del cobre en el período de 1970 a 2014 y herramientas de series de tiempo, para determinar un precio de tendencia o de largo plazo del cobre en el período de 2005 a 2014. El objetivo es recalcular la renta minera de la GMP-10, utilizando una serie del precio de largo plazo del cobre, de la que se ha removido el componente cíclico. En otras palabras, los precios del cobre que se observan cada año se transforman en una serie de tendencia de largo plazo suavizada, de la que se han eliminado las fluctuaciones de corto plazo.

Existen diversas herramientas para descomponer ciclos de tendencia, y entre ellas la más básica es la regresión lineal. En la literatura de series de tiempo se proveen metodologías estadísticas sofisticadas que cuentan con paquetes computacionales para aplicar a las series temporales observadas. Es probable que la metodología más utilizada y validada sea la del filtro HP (Hodrick y Prescott, 1997). Hemos optado por utilizar el filtro HP-100 - que se recomienda para las series anuales - y extraer a partir de él un precio de tendencia de la serie observada. El filtro HP-100 permite descomponer la serie de precios observados en un componente cíclico y otro de tendencia; de este modo, la serie tendencial del precio puede interpretarse como la secuencia temporal del precio de largo plazo. En el gráfico 5 se muestra con línea negra sólida la evolución del precio observado del cobre y con línea gris punteada el precio de tendencia de largo plazo. 


\section{Gráfico 5}

Precio internacional observado del cobre y precio de largo plazo obtenido con el filtro de Hodrick y Prescott, 1970-2015

(En dólares por libra) a

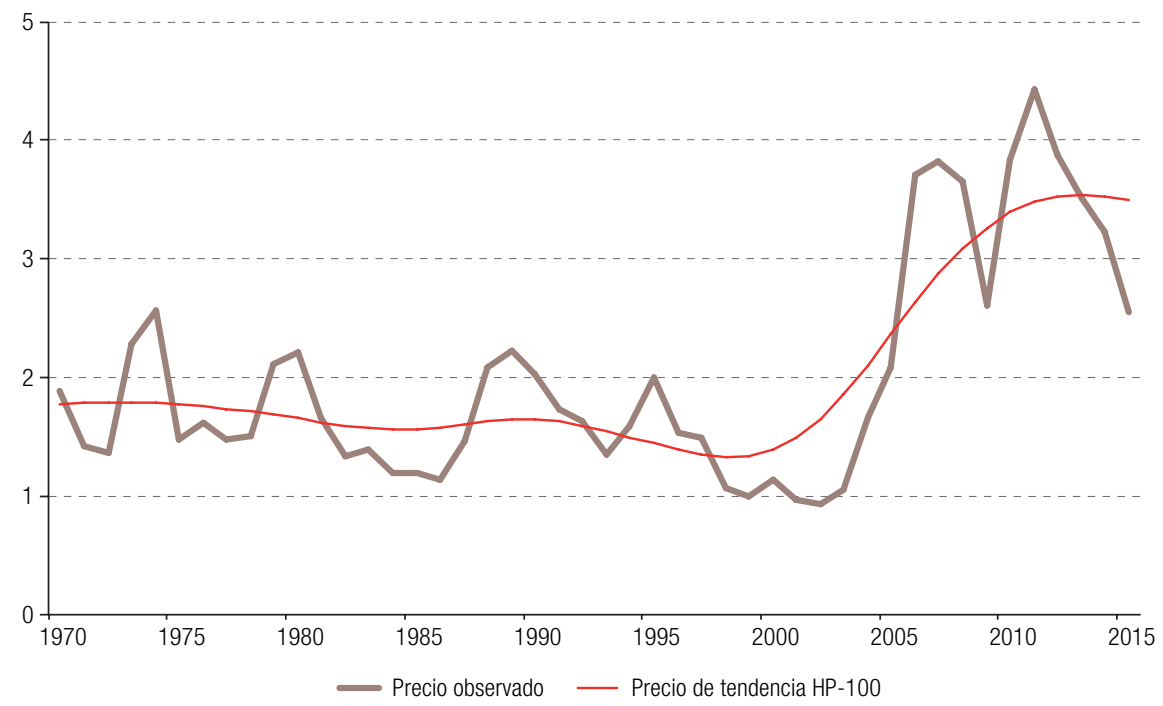

Fuente: Elaboración propia.

a En dólares de octubre de 2016.

Sobre la base del precio de tendencia del cobre en el período de 2005 a 2014, se vuelve a calcular la renta minera BM GMP-10. Los costos -incluido el de oportunidad - son exactamente los mismos que antes, lo único que cambia es el precio del cobre ${ }^{5}$.

\section{Resultados}

\section{Renta compensada GMP-10}

En esta sección se presenta la renta compensada GMP-10, que se estima substrayendo de la renta minera BM GMP-10 tanto el premio por el riesgo involucrado en las actividades de exploración minera, como la compensación que exige la volatilidad propia del precio del cobre. En el gráfico 6 se muestra la renta compensada GMP-10 que se estimó de ese modo. El ajuste realizado reduce la renta GPM-10 en 29.700 millones de dólares en el período de 2005 a 2014, solo debido a que los precios observados durante ese período son mayores que los de tendencia. Además, la corrección correspondiente a la deducción de la prima por riesgo de exploración reduce la renta estimada de la GMP-10 en otros 18.600 millones de dólares en el período considerado. De esta manera, al incorporar ambas correcciones, la estimación de la renta compensada GMP-10 resulta ser inferior a la del Banco Mundial en 48.300 millones de dólares en el período en su conjunto. Es decir, la renta minera BM GPM-10 en el período se reduce de 204.000 a unos 156.000 millones de dólares. Esto implica que la renta promedio anual del período de 2005 a 2014, corregida después de deducir

\footnotetext{
5 Hemos estimado la rentabilidad neta de las mineras que se proyecta para el año 2017 utilizando precios de tendencia del cobre sobre la base de la metodología de este estudio. El precio de tendencia del cobre de 2017 resulta ser de 2,82 dólares por libra, precio ligeramente superior al que informa el Consejo Minero (2,70 dólares por libra) y muy similar al esperado por Goldman Sachs (2,85 dólares por libra). Con esta proyección obtenemos una tasa media de rentabilidad neta sobre el capital antes de impuestos de casi el $40 \%$ en este año, en relación con las diez grandes mineras privadas. Esto equivale a unos 9.000 millones de dólares.
} 
ambos componentes, asciende a 15.600 millones de dólares, lo que corresponde al 6,9\% del PIB de Chile. Esto representa 4.800 millones menos que la renta minera BM GMP-10.

\section{Gráfico 6}

Chile: renta compensada GMP-10 por año, 2005-2014

(En miles de millones de dólares) ${ }^{\mathrm{a}}$

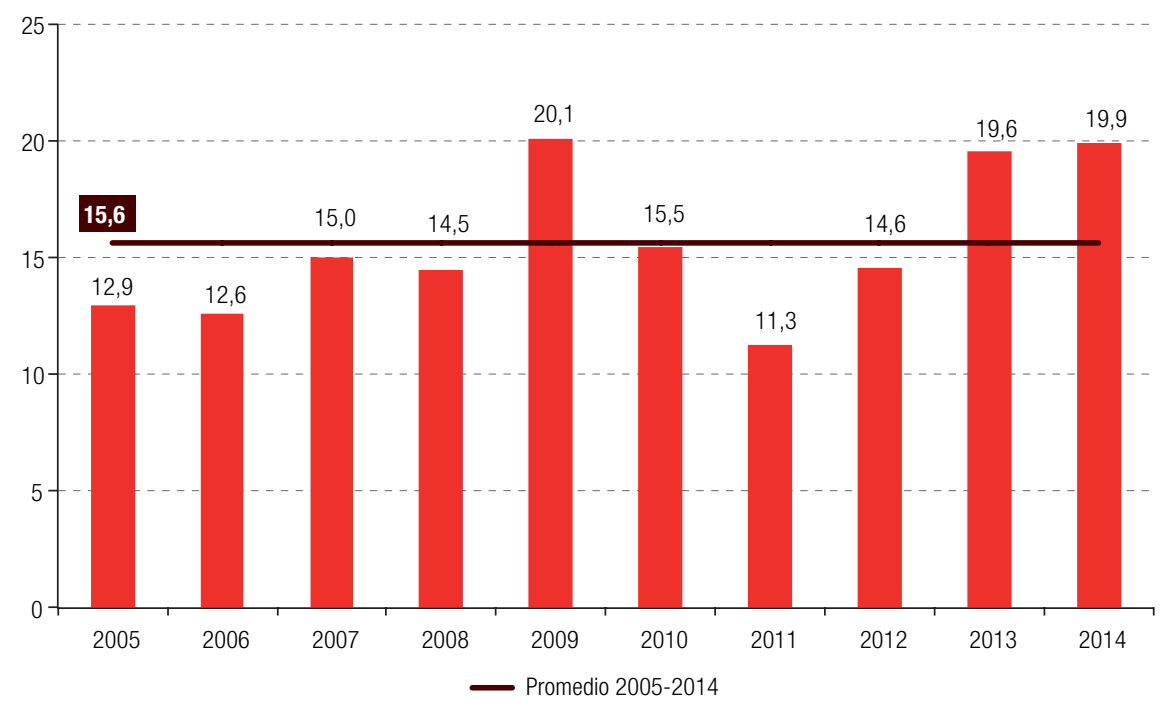

Fuente: Elaboración propia.

a En dólares de octubre de 2016.

\section{Renta graciosa apropiada GMP-10}

En la sección II.4 se definió el concepto de renta graciosa apropiada GMP-10 como la renta compensada GMP-10 menos los impuestos pagados por la gran minería privada cada año del período estudiado. Estos impuestos, establecidos en el código tributario chileno, son tres: i) impuesto de primera categoría, que grava las utilidades tributables de las empresas; ii) impuesto adicional, que grava las ganancias de fuente chilena obtenidas por personas naturales o jurídicas que no tienen domicilio ni residencia en Chile, y iii) impuesto específico a la minería (IEM), que grava las utilidades de la actividad minera obtenidas por un explotador minero. En el gráfico 7 se muestra la recaudación tributaria del fisco chileno proveniente de la GMP-10 (DIPRES, 2015), cuyo monto total en el período de 2005 a 2014 suma 41.600 millones de dólares.

Si a la renta compensada GMP-10 se le sustraen los impuestos pagados, se obtiene finalmente la renta graciosa apropiada GMP-10, que corresponde a 114.000 millones de dólares en el período de estudio. Es decir, unos 11.400 millones de dólares anuales, en promedio, lo que equivale al 5,1\% del PIB y al 23,3\% del gasto público durante el período. En el gráfico 8 se presenta la renta graciosa apropiada GMP-10, en dólares de octubre de 2016. (En el anexo A2 se encuentran los gráficos en los que dicha renta se expresa como porcentaje del PIB y del gasto público). 


\section{Gráfico 7}

Chile: recaudación tributaria del fisco chileno proveniente de la GMP-10, 2005-2014

(En miles de millones de dólares) ${ }^{\text {a }}$

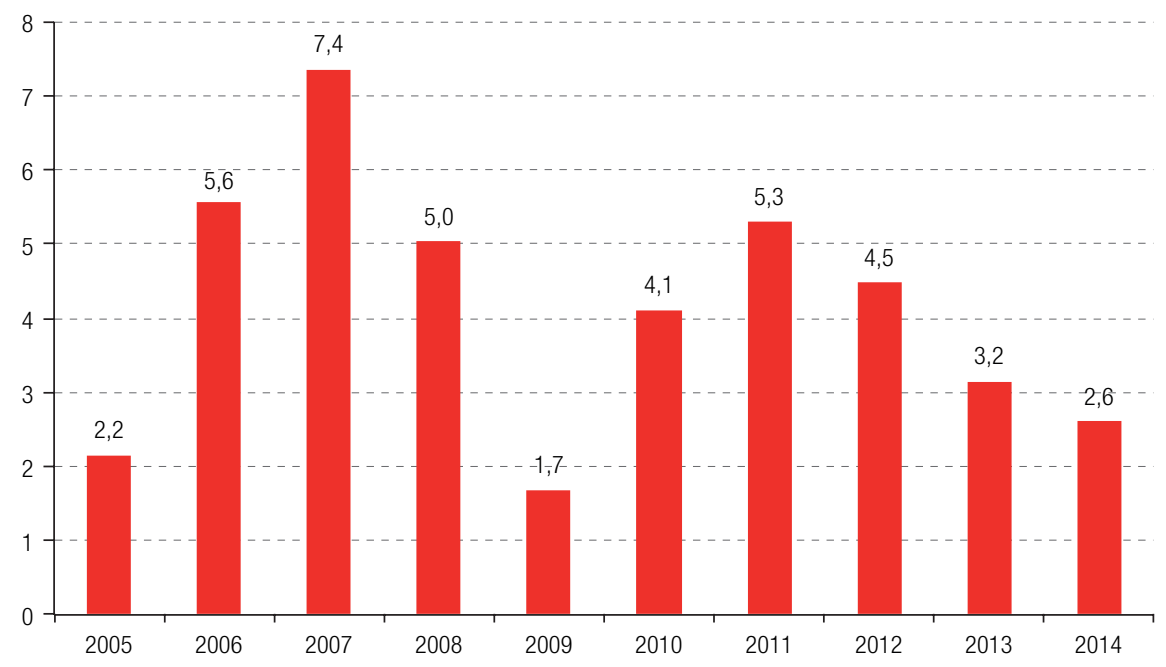

Fuente: Elaboración propia, sobre la base de Dirección de Presupuestos (DIPRES), "Evolución, administración e impacto fiscal de los ingresos del cobre en Chile”, Santiago, Ministerio de Hacienda, 2015 [en línea] http://www.dipres.gob.cl/572/ articles-133158_doc_pdf.pdf.

a En dólares de octubre de 2016.

Gráfico 8

Chile: renta graciosa apropiada GMP-10 por año, 2005-2014

(En miles de millones de dólares) ${ }^{a}$

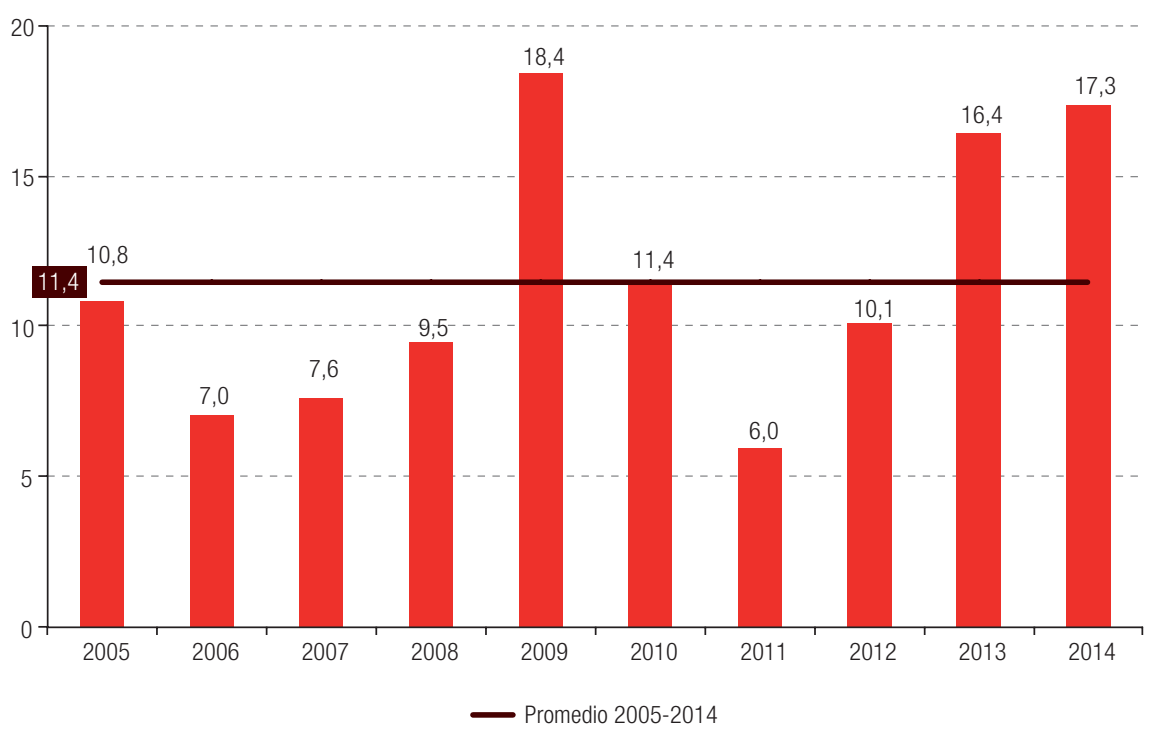

Fuente: Elaboración propia.

a En dólares de octubre de 2016. 


\section{Resumen de los resultados}

En el gráfico 9 se presentan los montos totales de cada una de las cuatro rentas económicas definidas en este trabajo, en el período de 2005 a 2014. Los montos se expresan en millones de dólares de octubre de 2016. (La evolución temporal se encuentra en el anexo A3).

Gráfico 9

Chile: rentas mineras totales por tipo, 2005-2014

(En millones de dólares) ${ }^{\mathrm{a}}$

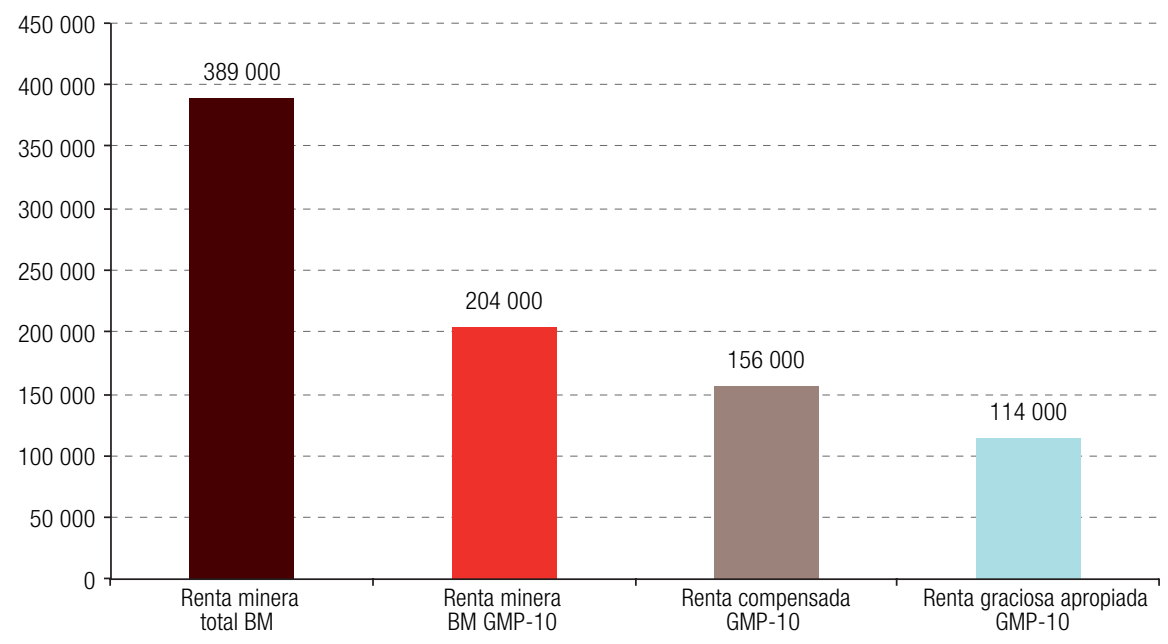

Fuente: Elaboración propia.

a En dólares de octubre de 2016.

\section{Análisis de sensibilidad}

Como se ha mencionado, en este estudio se ha considerado una probabilidad de éxito en la exploración del 2,5\%, la más baja de la literatura. Entre otros supuestos, en ella se considera que el conocimiento de la geología del territorio es nulo. Chile es considerado un sitio minero, lo que significa que ya existe un gran conocimiento de las características geológicas del país (SERNAGEOMIN, 2013). Por ese motivo, en estudios recientes se recomienda un valor del $10 \%$ al $20 \%$, en lugar del 2,5\% (Bartrop y Guj, 2009).

Por otra parte, sobre la base de un estudio de CORFO (FCH/Alta Ley/CORFO,2015), se ha considerado que los costos directos unitarios de la GMP-10 son superiores a los de CODELCO, es decir, un promedio de alrededor de 1,6 dólares por libra en el período considerado. Sin embargo, el estudio de la consultora internacional Mining Benchmark (Mining Press, 2013) indica un costo de solamente 1,21 dólares por libra en el período. Esta última estimación es tal vez más creíble que la de CORFO, considerando el consenso de los analistas y el hecho de que los yacimientos de Codelco son, en general, más antiguos y de menor ley que los privados.

Pese a que el presente trabajo ha tenido por objeto calcular una renta económica mínima y conservadora, presentamos aquí un análisis de sensibilidad con supuestos más razonables concernientes a la probabilidad de éxito de la exploración y a los costos unitarios, sobre la base de los estudios que se mencionan en los párrafos anteriores. En el cuadro 1 se presenta una matriz de rentas graciosas apropiadas por la GMP-10. Como se puede observar en dicho cuadro, la renta apropiada con el supuesto del 10\% de probabilidad de éxito y el costo unitario que se indica en Mining Benchmark asciende a 163.000 millones de dólares, cifra que supera en más del 30\% nuestra estimación base. Estas simulaciones ilustran cuantitativamente cuán conservadora es dicha estimación. 
Cuadro 1

Chile: renta graciosa apropiada GMP-10 en seis escenarios, 2005-2014

(En miles de millones de dólares)

\begin{tabular}{ccc}
\hline $\begin{array}{c}\text { Probabilidad de éxito de la exploración } \\
\text { (en porcentajes) }\end{array}$ & $\begin{array}{c}\text { Costo Corfo } \\
\text { (1,60 dólares por libra) }\end{array}$ & $\begin{array}{c}\text { Costo Mining Benchmark } \\
\text { (1,21 dólares por libra) }\end{array}$ \\
\hline 2,5 & 114 & 145 \\
\hline 5,0 & 126 & 157 \\
\hline 10,0 & 132 & 163 \\
\hline
\end{tabular}

Fuente: Elaboración propia.

a En dólares de octubre de 2016.

\section{Algunas comparaciones}

Aquí se ha estimado que, en el período de 2005 a 2014, la renta graciosa apropiada GMP-10 ascendió a un total de 114.000 millones de dólares. Esta cifra significa un flujo promedio anual equivalente al 5,1\% del PIB del país. Para dimensionar esta cifra, aquí se dan algunos ejemplos que ilustran su magnitud.

Los recursos regalados por año promediaron 11.400 millones de dólares durante el período de 2005 a 2014. Se ha estimado que la gratuidad de la educación en el país, entendida como el financiamiento estatal completo y en todos los niveles de la educación, requiere de recursos equivalentes a casi 5.000 millones de dólares adicionales al año. Además, se estima que la reforma tributaria promulgada recientemente va a recaudar 6.000 millones de dólares anuales como máximo.

Es decir, con la riqueza que se regaló anualmente a estas grandes empresas transnacionales durante el período de 2005 a 2014, se podría haber financiado la educación gratuita completa y, con los 6.400 millones de dólares restantes, se podría haber mejorado el sistema de salud y pensiones de manera definitiva. Todo esto sin necesidad de hacer una compleja reforma tributaria cuyos efectos sobre la inversión y la eficiencia económica son inciertos.

Finalmente, si en el país se hubiesen ahorrado estos 114.000 millones de dólares y estos se hubieran invertido como fondos soberanos, se obtendría un flujo anual permanente de rentas superior a 7.000 millones de dólares, asumiendo un patrón de inversión conservador. Es decir, el país tendría cada año un flujo estable anual de recursos, independiente de las fluctuaciones del precio del cobre, equivalente a casi todo el gasto público en salud, lo que implica que se podrían doblar los servicios públicos de salud del país de manera permanente.

Por último, en Chile se realiza cada año la Teletón, actividad solidaria nacional para financiar el cuidado y la rehabilitación de personas con discapacidades crónicas o transitorias. En 2016, se recaudó una cifra de aproximadamente 47 millones de dólares. Con el monto entregado por gracia a la gran minería en el período de 2005 a 2014, se podrían financiar unas 2.420 Teletones del año 2016.

\section{Reflexiones finales}

Quizás la pregunta más relevante que surge de las estimaciones aquí realizadas es la siguiente: ¿quién o quiénes regalan graciosamente esta enorme cantidad de recursos a estas empresas? No cabe duda de que la respuesta debe buscarse entre quienes permiten, desde el Poder Ejecutivo y el Parlamento del país, que las leyes que posibilitan este absurdo regalo sigan vigentes. Las autoridades políticas de países hoy desarrollados, como el Canadá, los Estados Unidos y Noruega, cambiaron sus legislaciones hace tiempo para permitir que se gravara una altísima proporción de las rentas mineras y los recursos naturales, lo que les permitió detener el despilfarro de los recursos pertenecientes a todos 
sus conciudadanos y sentar las bases para fortalecer sus economías y los derechos sociales en sus países (Taylor y otros, 2004; Guj, 2012; Figueroa, López y Gutiérrez, 2013; Bowie, 2016).

A nuestro entender, el hecho de que Chile sea incapaz de recuperar estas enormes rentas para todos los chilenos se debe también, en gran parte, a la falta de información de la ciudadanía sobre la magnitud de las pérdidas ocasionadas por la reticencia de las autoridades políticas y económicas a desarrollar los mecanismos necesarios para captar estas rentas. El presente trabajo puede considerarse como un aporte destinado a corregir esta desinformación.

Cerramos este trabajo recordando la cita del Ministro de Hacienda Rodrigo Valdés presentada en el inicio de este artículo. Al parecer, la pregunta que debería hacerse "todo chileno" tendría que ser más amplia de lo que propone el Ministro y no debería referirse a "cómo usar un peso adicional" sino a por qué Chile no cuenta, no con un peso adicional, sino con los miles de millones de dólares que significan las rentas graciosamente regaladas a las mineras privadas cada año, que equivalen a muchos puentes, a muchos colegios, al salario de muchos miles de trabajadores del sector público y a las pensiones de muchos miles de pensionados del país. La respuesta a esta pregunta hay que pedírsela en especial al Ministro y a sus antecesores, así como a los presidentes de la República y a los parlamentarios de las últimas décadas. Si no se exige dicha respuesta, esta enorme riqueza nacional se seguirá dilapidando y los chilenos continuarán ignorando la lúcida advertencia del Presidente Balmaceda citada al comienzo de este trabajo, sobre el riesgo de transformar "...esta vasta y rica región...en una simple factoría extranjera..." (Balmaceda, 1889).

\section{Bibliografía}

Balmaceda, J. M. (1889), "Mensaje al Congreso", Santiago, 1 de junio.

Banco Mundial (2016), "World Development Indicators" [en línea] www.worldbank.org.

(2011), The Changing Wealth of Nations: Measuring Sustainable Development in the New Millennium, Washington, D.C.

Bartrop, S. y P. Guj (2009), "Estimating historical probabilities of discovery in mineral exploration", CET Quarterly News, No 8, Crawley, Centre for Exploration Targeting, junio.

Bowie, C. (2010), A Review of Mining Royalties in Australia, Brisbane, MinterEllison.

Brandt, N., P. Schreyer y V. Zipperer (2013), "Productivity measurement with natural capital", OECD Economics Department Working Papers, № 1092, París, Organización de Cooperación y Desarrollo Económicos (OCDE).

Castillo, R. (2015), El cobre: anatomía del mayor fraude minero en Chile, Santiago, Andros Impresores.

COCHILCO (Comisión Chilena del Cobre) (2015), Anuario de estadísticas del cobre y otros minerales, 19962015, Santiago.

Correa, F. (2016), “¿Perdimos la oportunidad con el cobre?”, Documento de Trabajo, № 1, Santiago.

DIPRES (Dirección de Presupuestos) (2015), "Evolución, administración e impacto fiscal de los ingresos del cobre en Chile", Santiago, Ministerio de Hacienda [en línea] http://www.dipres.gob.cl/572/articles-133158_ doc_pdf.pdf.

El Mercurio (2017), "Alto Maipo y el riesgo de emprender", Santiago, 22 de enero [en línea] http://www. economiaynegocios. cl/noticias/noticias.asp?id=329285.

FCH/Alta Ley/CORFO (Fundación Chile/Alta Ley/Corporación de Fomento de la Producción) (2015), "Hoja de ruta de la minería 2035", Santiago [en línea] http://programaaltaley.cl/wp-content/uploads/2015/12/ Informe-Hoja-de-Ruta-2015.pdf.

Figueroa, E., R. E. López y P. Gutiérrez (2013), "Structural barriers to long-term productivity growth and sustainable development: lessons from the 'implicit industrial policy' imbedded in Chile's tax system", documento presentado en el XXXI Congreso Internacional de la Asociación de Estudios Latinoamericanos, Washington, D.C.

Guj, P. (2012), Mineral Royalties and Other Mining-specific Taxes, Crawley, International Mining for Development Centre. 
Hammes, J. K. (1985), "Economic rent considerations in international mineral development finance", Finance for the Minerals Industry, C. R. Tinsley y M. E. Emerson, Society for Mining Metallurgy.

Hodrick, R. J. y E. C. Prescott (1997), "Postwar U.S. business cycles: an empirical investigation", Journal of Money, Credit, and Banking, vol. 29, № 1, Blackwell Publishing.

López, R. y E. Figueroa (2014), "Generación y distribución óptima de la renta económica en los sectores de recursos naturales en Chile", Santiago, Departamento de Economía, Universidad de Chile.

Mining Press (2013), "Las grandes mineras de Chile celebran más leyes de cobre" [en línea] http://www. miningpress.com/nota/249996/grandes-mineras-celebran-avance-en-las-leyes-de-cobre.

Ministerio de Hacienda (2015), Informe anual fondos soberanos, 2015, Santiago.

Poblete, N. (2015), "El cobre chileno y su renta futura", tesis, Santiago, Universidad de Chile.

Ricardo, D. (2005), The Works and Correspondence of David Ricardo, P. Sraffa (ed.), Indianapolis, Liberty Fund.

SERNAGEOMIN (Servicio Nacional de Geología y Minería) (2013), "Concesiones mineras de exploración en Chile", Santiago.

Shepherd, A. R. (1970), "Economic rent and the industry supply curve", Southern Economic Journal, vol. 37, $N^{\circ} 2$, Wiley.

Taylor, A. y otros (2004), When the Government is the Landlord, The Pembina Institute.

Tollison, R. D. (1982), "Rent seeking: a survey", Kyklos, vol. 35, N 4, Wiley.

Valdés, R. (2016), "Valdés y reajuste de 7,5\% en sector público: 'está lejos de lo que Chile puede abordar'”, La Tercera, Santiago, 25 de agosto [en línea] http://www.latercera.com/noticia/valdes-y-reajuste-de-75en-sector-publico-esta-lejos-de-lo-que-chile-puede-abordar/.

Wessel, R. (1967), "A note on economic rent", American Economic Review, vol. 57, № 5, Nashville, Tennessee, American Economic Association. 


\section{Anexo A1}

\section{Descuentos por venta de concentrado de cobre}

Entre 2005 y 2014, CODELCO vendió en promedio un 14\% de su cobre en forma de concentrado. A efectos de calcular los ingresos por venta a precio de mercado, se debe corregir por este efecto, como se detalla a continuación (COCHILCO, 2015):

i) La cantidad de cobre contenido en el concentrado debe reducirse considerando dos efectos: la humedad (el 10\% de la masa), y el costo de fundición y refinación (el 15\% de la masa).

ii) Además, se deben descontar tres costos por tonelada de cobre: 140 dólares por maquila, 10 dólares por el efecto escala y un máximo de 400 dólares por las pérdidas asociadas a demás minerales contenidos en el concentrado.

Dado lo anterior, se define:

$q_{b}=$ cantidad bruta de cobre en el concentrado;

$q_{e}=$ cantidad de cobre efectivo en el concentrado, esto es, luego de aplicar las dos correcciones descritas en el punto i) anterior;

$q_{p}=$ pérdida o diferencia entre la cantidad bruta y la efectiva de cobre, es decir, $q_{p}=q_{b}-q_{e}$, y

$z$ = suma de los costos adicionales especificados en el punto ii) anterior, por tonelada efectiva de cobre en el concentrado.

Así, la renta asociada a CODELCO se puede escribir en función de c1, el costo directo unitario. Esta forma es equivalente a la que se presenta en la ecuación (2) de este estudio. Se presenta el detalle de la renta asociada a CODELCO, considerando las correcciones por cobre en forma de concentrado. (Las demás variables corresponden a las definidas en la sección IV.2.b).

$$
R_{b m, \text { Cod }}=p \cdot\left(q_{C o d}-q_{p}\right)+S_{C o d}-c_{1} \cdot q_{C o d}-z \cdot q_{e}(r+\delta) \cdot K_{C o d}
$$




\section{Anexo A2}

\section{Renta graciosa apropiada GMP-10}

Gráfico A2.1

Chile: renta graciosa apropiada GMP-10 por año, como proporción del PIB, 2005-2014

(En porcentajes)

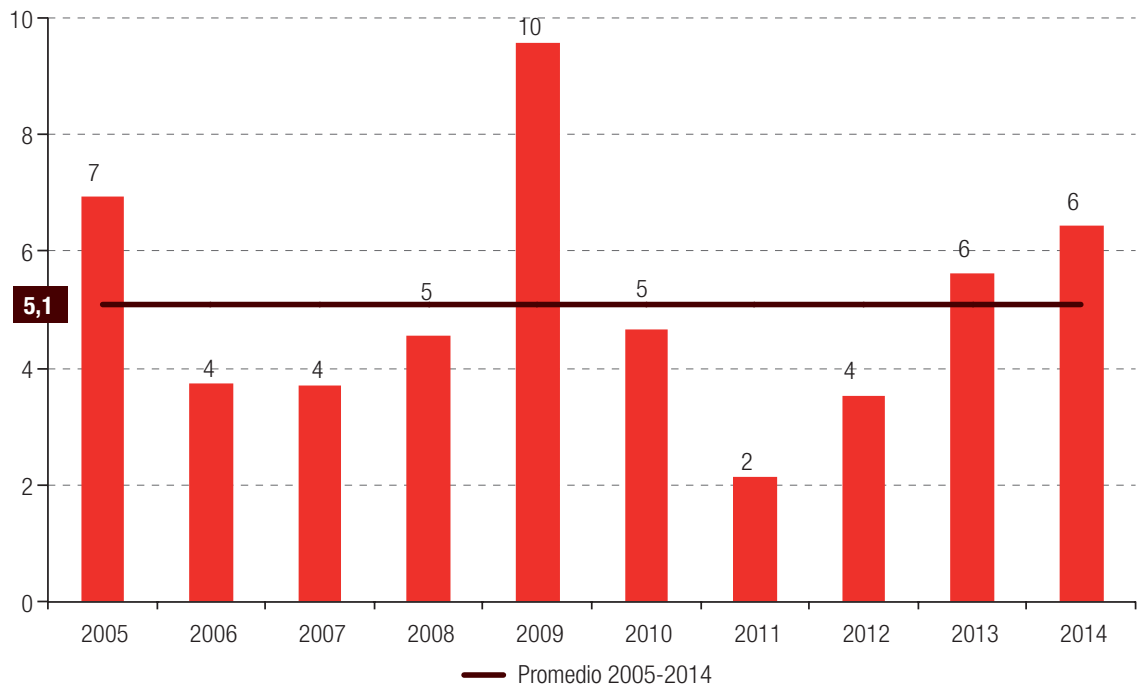

Fuente: Elaboración propia.

Gráfico A2.2

Chile: renta graciosa apropiada GMP-10 por año, como proporción del gasto público, 2005-2014 (En porcentajes)

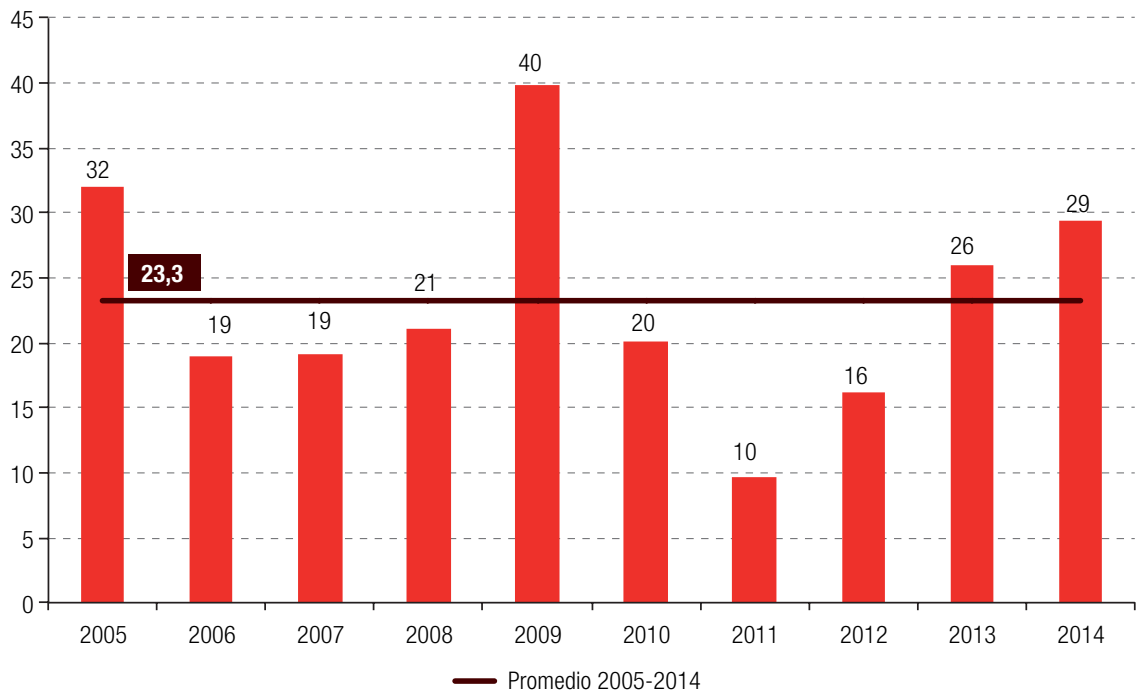

Fuente: Elaboración propia. 


\section{Anexo A3}

\section{Evolución temporal de los cuatro tipos de rentas}

En el gráfico A3.1 se muestran las estimaciones anuales obtenidas en relación con los cuatro tipos de rentas económicas en el período de 2005 a 2014, en miles de millones de dólares de octubre de 2016. La línea continua de color gris ubicada más cerca del eje horizontal corresponde a la renta graciosa apropiada GMP-10. En este gráfico se ilustra el hecho de que la estimación de esta renta constituye una estimación "piso".

\section{Gráfico A3.1}

Chile: comparación de las cuatro rentas económicas de la minería chilena estimadas en este estudio, 2005-2014

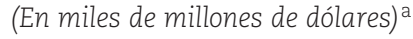

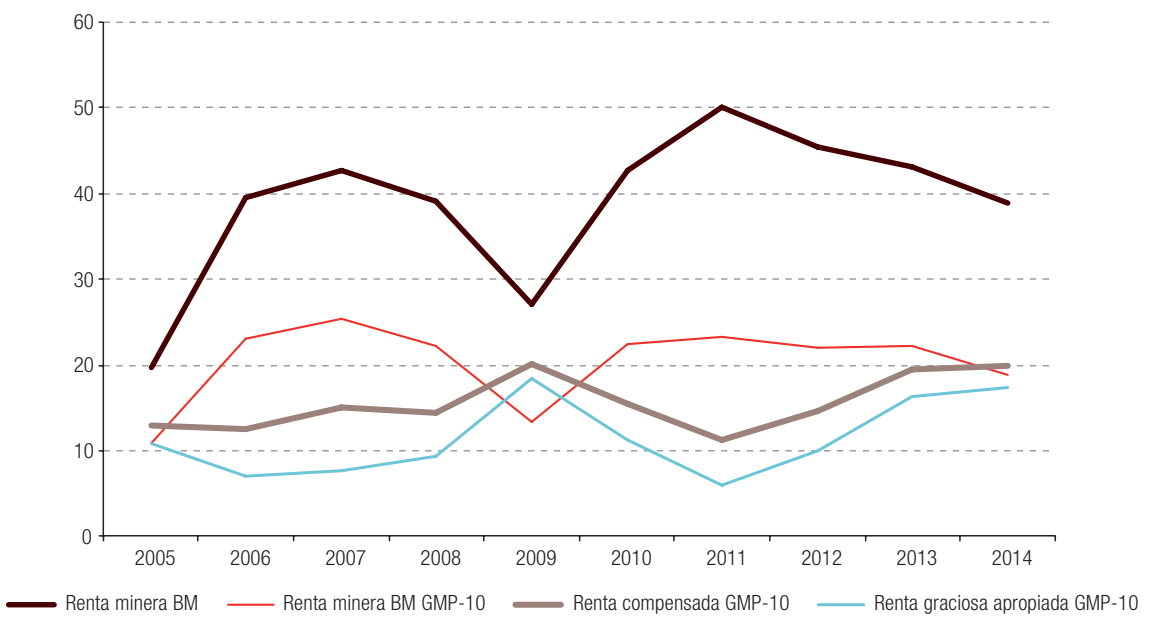

Fuente: Elaboración propia.

a En dólares de octubre de 2016. 